\title{
RESEARCH REPORT \\ RISK OF CARDIAC DISEASES DUE TO HYPERTENSION DURING TREADMILL EXERCISE AMONG ECTOMORPHS
}

\section{ABSTRACT \\ OBJECTIVES}

To determine the effects of exercises by using treadmill leading to cardiac diseases due to HTN response of exercise among ectomorph male and female.

\section{STUDY DESIGN}

An experimental study design was used.

\section{STUDY SETTINGS \& PARTICIPANTS}

30 students that were studying in a reputed institution with BMI of 18.5 (both male and female) were the part of this study.

\section{INTERVENTIONS}

Heart rate and blood pressures were measured through Heart Rate Monitor, Mercury Sphygmomanometer, Weighing Scale Treadmill, and Stadiometer was used to collect data. The data was analyzed through SPSS.16, through paired sample t test.

\section{RESULTS}

No statistically significant differences were obtained in post exercise B.P among ectomorph men and women where as significant difference between pre-exercise and post-exercise heart rates on ectomorph were obtained.

CONCLUSIONS

B.P and H.R are two significant indicators in our body that give signal about many cardiac diseases silently existing in our body. Our study concluded that the body responses to exercise are similar in both ectomorphs male and female; therefore ectomorphs have equal risk factor for cardiac diseases.

\section{KEYWORDS}

Ectomorph, exaggerated blood pressure, heart rate, exercise test, treadmill, Mercury Sphygmomanometer, Weighing Scale, Stadiometer.

\section{Beenish Zafar}

Senior Lecturer

Ziauddin College of Physical

Therapy Ziauddin University

beenish_zafar@yahoo.com

\section{Najeeb Khattak}

DPT, Student

Ziauddin College of Physical

Therapy

Ziauddin University

\section{Mahwish Fiza}

DPT, Student

Ziauddin College of Physical

Therapy

Ziauddin University

[Zafar B, Khattak N \& Fiza M. Risk of cardiac diseases due to hypertension during treadmill exercise among ectomorphs. Pak. j. rehabil. 2016;5(1):39-44] 


\section{INTRODUCTION}

Today we are living in a modern era, in which world has become more developed in terms of science and technology, unfortunately this advancement in science and technology decreases outdoor activity, that leads to many fatal non communicable diseases like hypertension, diabetes and cancer, so exercises have a beneficial effect on our body, for this purpose we want to find the responses occur in our body due to exercise, for e.g. blood pressure and heart rate.

There are three basic human body types i.e. Ectomorph, Endomorph and Mesomorph. The ectomorphs are recognized by typical lean, lack of much fat or muscle tissue'because of fast metabolism hence the risk of getting low body fat ${ }^{2}$.Their muscle growth takes too much time to become hypertrophied. Similarly people who are ectomorph put extra efforts for obtaining muscular body weight. On the other side the endomorphs have capability to grow muscle mass more efficiently than ectomorphs, whereas losing body weight is too much complicated for endomorphs as compare to ectomorphs. At last the mesomorphs contain predominance of muscles, connective tissues and bones. They have an equal capability to lose or gain weight without any complications. These types of people have also decreased chances of non communicable diseases occurrence.

Majority of coronary artery diseases are results of high blood pressure, rate of hospitalization and death is highly common in the adults ${ }^{2-4}$. It has been ruled out that the role of blood pressure (BP) response to exercise is one of the risk factor for causing hypertension ${ }^{2-8}$. The systolic blood pressure (SBP) response to elevate heart rate (HR) and $\mathrm{VO}_{2}$ in treadmill and cyclic ergo meter has not been obviously described up till now ${ }^{9-13}$. Likewise these conclusions point out that the quantity of elevation in systolic blood pressure on the cyclic ergo meter is probable to be greater than the quantity of raise in systolic blood pressure on the treadmill'. Furthermore It was documented that $\mathrm{VO}_{2}$ max gained during treadmill was $6 \%$ to $25 \%$ which is greater than $\mathrm{VO}_{2}$ max obtained during cyclic ergo meter ${ }^{14-20}$. The difficulty with utilizing Systolic blood pressure at a steady workload to calculate the blood pressure reaction is that persons will carry out at different percentages of their greatest capacity. Whereas it has been suggested that the progress of hypertension is predictable by a pre hypertensive condition that can be established by unusual cardiovascular activity to behavioral challenges and environment ${ }^{21}$, such as cold water absorption, mental arithmetic tasks, isometric and dynamic bodily stress tests. One of the most beneficial affect may be exercise stress test ${ }^{22,23}$ which is now broadly used in hospitals to diagnose coronary heart disease and in sports and occupational medicine to assess cardio respiratory fitness. However, its accuracy for identifying persons on risk factor is more prone to develop hypertension and as a test for the indicator of hypertension onset is quietly being discussed. Earlier studies indicating that this issue has used unlikely definitions for an exaggerated Blood Pressure response to exercise, some are based completely on Systolic Blood Pressure whereas others are based on both Systolic and Diastolic Blood Pressure ${ }^{24}$. Likewise it was mentioned that there is no significant difference in mean arterial pressure between the male and female populations, which indicated that both genders have equal risk factor for occurring cardiovascular diseases.

Middle aged males and females have a more dominant parasympathetic and sympathetic regulation of heart rate but this gender-related difference does not appear in the older population ${ }^{25}$. The fat tissue description between both gender are necessary here because the division of adipose tissue thickness, fat mass and quantity were studied in four regions in randomly selected middle aged men and women in which the sample size was 930 obese persons. The randomly selected males were found to have highest adipose tissue thickness in the abdominal region comparative to females. Female participants found to have fat deposition on gluteal and femoral regions. Likewise fat mass increases with increasing body fat up to a maximal size of approximately 0.7 - $0.8 \mathrm{micro}$ grams/cell in each area $^{26}$. It has been stated that there are some anatomical and physiological differences between males and females. Females have smaller, shallower, wider and more circular pelvic cavity as well as smaller bones and lower bone density than males. In addition, the average adult female contains 10\% more body fats than male. When discussing about cardiovascular system, the females consist of smaller heart, lower stroke volume and $\mathrm{Vo}_{2}$ max and $10 \%$ lesser Hemoglobin level than males, naturally, women have smaller muscle fibers and 30 to $50 \%$ less upper body strength in comparison to male muscular system ${ }^{27}$.

A treadmill is a machine which broadly used for walking or running purpose. In addition it is used by the people who are physically fit or want to be physically fit and it offers the highest potential load on cardio pulmonary system ${ }^{28}$. The treadmill test can influence the magnitude to measure $\mathrm{Vo}_{2}$ max, with the graded running test giving the maximum value ${ }^{28}$. Subject of the study were selected according to their body types which divided into ectomorph, mesomorph and endomorph. In a study, researcher arranged a noninvasive treadmill protocol for determining $\mathrm{VO}_{2} \mathrm{max}$ in 1963 in patients with heart disease, pulmonary disease, athletes and young active individuals ${ }^{28}$.

Maximum heart rate can be evaluated by using Bruce protocol or exercise treadmill stress test, but it 
required much time for testing. Similarly we can also use treadmill to detect the elevated response of blood pressure during exercise ${ }^{29}$. If there is any rise in cardiac output or total vascular confrontation, the systolic BP will be raised. This rise in blood pressure helps to indicate the elevated vascular blood flow and this will reduce the blood circulation to muscles. During the starting stages of exercise, cardiac output is increased due to rise in stroke volume and heart rate.

During the exercise the quantity of blood pumped by heart is increased because oxygen demand to muscles increase whereas in heart rate it is an involving factor that influence the Sino-Atrial node which controls heart rate throughout the signals coming from sympathetic and Para sympathetic nervous systems.

Studies have shown that the general raise in heart rate through the exercise is due to decreased Para sympathetic tone. Furthermore, rise in heart rate due to increased work rates by the stimulation of Sino-Atrial and Atrio-Ventricular nodes by sympathetic nervous system.

Maximal oxygen utilization ( $\mathrm{VO}_{2} \mathrm{max}$ ) is the principal amount of oxygen a person can get from inhaled air while doing dynamic exercise; it includes a larger part of muscle mass. It is also admitted that the best calculation of cardiovascular fitness and exercise ability. $\mathrm{VO}_{2}$ max represents the quantity of oxygen transported and used in cellular metabolism ${ }^{30}$. Likewise when dynamic exercise is in progress Oxygen requirement rapidly increases, similarly $\mathrm{VO}_{2}$ max alters by sex, age, exercise habits, heredity, and cardiovascular status. Maximum values of $\mathrm{VO}_{2}$ max take place among the ages of 15-30 years and turn down gradually with increase in age ${ }^{30}$. In addition to this the $\mathrm{VO}_{2}$ max is poor in females comparative to males because they have low hemoglobin, less blood volume and decreased muscle mass.

On treadmill training the body has different exaggerated responses. The body's reaction that exaggerates during any activity or exercise may be circulatory strain, heart rate, respiratory rate, metabolic rate, and so forth. Motivation behind the study is to focus the diverse overstated reactions of systolic circulatory strain on ectomorphs in distinctive sexual orientation.

\section{METHODOLOGY}

\section{Study Design}

This study was an experimental study.

Sampling technique

Simple randomized sampling was used to collect data.

Study setting and participants

30 students studying in the DPT program of reputed institution with BMI below18.5 of both genders were included in this study

Study duration

Six months

Inclusion and exclusion criteria

Healthy individuals aged 19-24years, not using any prescribed medication

Data collection Tool

Treadmill, Heart Rate Monitor, Mercury Sphygmomanometer, Weighing Scale and Stadiometer were used to collect data.

Ethical consideration

The Research is approved by the ethical review committee of the university. Participant's demographic information was kept confidential and was only accessed by the authorized personal.

Data analysis

The data was analyzed through SPSS 16, through paired sample T test.

Outcome Measures

Systolic blood pressure

\section{Collection of Data}

30 active and healthy individuals without the diagnosis of having any disease were selected. They are well informed for conduction of comprehensive test on Tread mill. They all were educated about the Bruce protocol or Graded Exercise Test. The criteria for participation are nonsmoking, age (>19 and $<30$ ), non medication users; and without orthopedic condition which can be increased by exercise. These additional bases are collected for documented constant Cardio-Vascular response to Bruce protocol exercise test ${ }^{9}$. Subject of the study is selected according to their body type which divided into ectomorph, mesomorph and endomorph. Individual record, known consent as the experiment conducted. The correlated hazards and the advantages are totally explained for participation?. Exercise tests

Study was conducted in a fitness gym located I the university and instructions were given to participants to avoid smoking and strenuous exercise at least forty eight hours before the test conducted. They were weighted in $(\mathrm{kg})$ and their height was measured in (cm), and participants then completed a medical history and physical activity questionnaire. Subjects exercised on the Treadmill were asked to follow the Bruce protocol ${ }^{28}$. Treadmill started from $2.74 \mathrm{~km} / \mathrm{hr}$ and inclination of $10 \%$ in every 3 minutes was increased in inclination by $2 \%$ side by side addition of speed ${ }^{9}$.Room temperature was maintained between $\left(20^{\circ} \mathrm{C}-24^{\circ} \mathrm{C}\right)$ after ten-minute seated resting position. The Heart rate and Blood pressure were documented at steady state with a Heart Rate Monitor and Mercury Sphygmomanometer?. Normal BP is defined as baseline blood pressure < 140/90 $\mathrm{mm} \mathrm{Hg}$ and Uncontrolled BP as baseline BP > $140 / 90 \mathrm{~mm} \mathrm{Hg}$ followed by the guidelines of the eight results of the Joint National Committee (JNC 8) on recognition, assessment, and management for exaggerated $\mathrm{BP}^{28}$. They exercised until exercise was completed and required criteria were made. $\mathrm{BP}$ and HR was monitored again and documented. 
Measurements were taken by the same individuals for all subjects using the same calibrated mercury sphygmomanometer and digital heart rate monitor.

\section{RESULT}

Difference in heart rate response to exercise in ectomorph males and females

The value of $p$ is 0.000 by paired samples test which shows that there is a significant difference between heart rate before and after exercise. (Table 1)

Table 1

Paired Samples Test

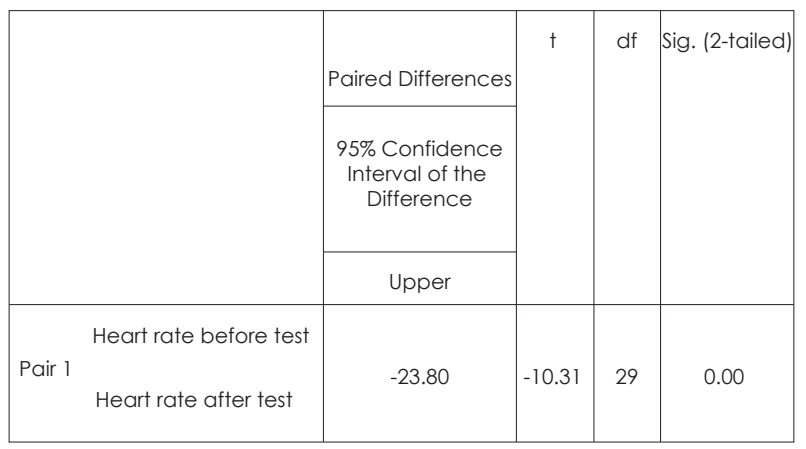

Group Statistics

\begin{tabular}{|c|c|c|c|c|}
\hline Gender & N & Mean & Std. Deviation & Std. Error Mean \\
\hline $\begin{array}{c}\text { Total difference in Male } \\
\text { Heart Rate Female }\end{array}$ & 15 & 35.20 & 16.70 & 4.31 \\
\hline
\end{tabular}

The value of $p$ is 0.055 by independent sample test which shows that there is no significant difference in heart rate after exercise among males and females (Table 2)

\begin{tabular}{|l|c|c|c|}
\hline \multirow{2}{*}{ Table 2 } & \multicolumn{2}{|c|}{ t-test for Equality of Means } \\
\cline { 2 - 4 } & df & $\begin{array}{c}\text { Sig.(2- } \\
\text { tailed) }\end{array}$ & $\begin{array}{c}\text { Mean } \\
\text { Difference }\end{array}$ \\
\hline $\begin{array}{l}\text { Total differences in } \\
\text { Heart Rate }\end{array}$ & 28 & .05 & 11.00 \\
$\begin{array}{l}\text { Equal variances not } \\
\text { assumed }\end{array}$ & 26.49 & .05 & 11.00 \\
\hline
\end{tabular}

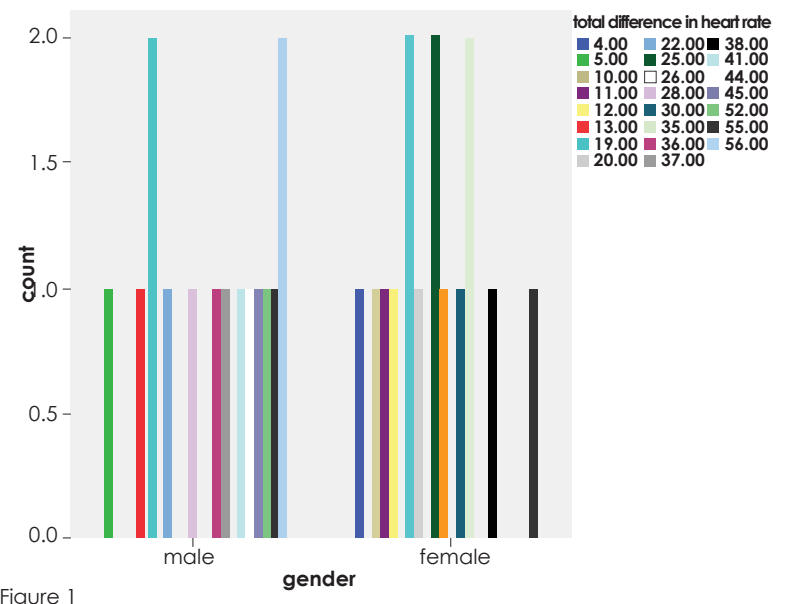

Figure

Difference in Blood Pressure response to exercise in ectomorph males and females

The value of $p$ is 0.503 by independent sample test which shows that there is no significant difference in blood pressure after exercise among males and females (Table 3).

\begin{tabular}{|c|c|c|c|}
\hline \multicolumn{2}{|c|}{ Table 3 } & \multicolumn{2}{|c|}{ t-test for Equality of Means } \\
\cline { 2 - 4 } & Df & $\begin{array}{l}\text { Sig. (2- } \\
\text { tailed) }\end{array}$ & $\begin{array}{l}\text { Mean } \\
\text { Difference }\end{array}$ \\
\hline $\begin{array}{l}\text { Total difference in } \\
\text { Blood Pressure } \\
\quad \begin{array}{l}\text { Equal variances assumed variances not } \\
\text { assumed }\end{array}\end{array}$ & 28 & 0.50 & 2.66 \\
\hline \multicolumn{2}{|c|}{27.96} & 0.50 & 2.66 \\
\hline
\end{tabular}

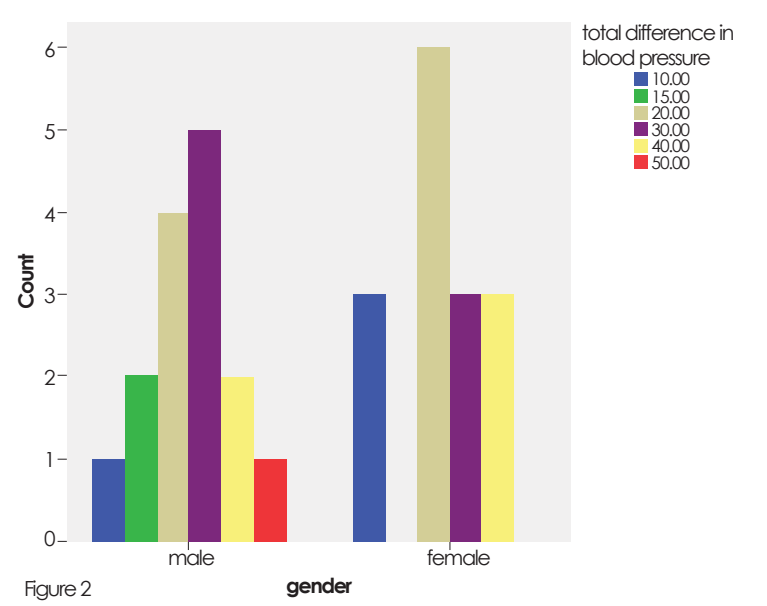




\section{DISCUSSION}

Total no. of sample is 30 , it included both male and female, 15 participants were male and 15 were females.

According to figure 2, in males there was only one participant whose blood pressure difference before and after exercise was $10 \mathrm{~mm} \mathrm{Hg}$, however there was a blood pressure difference of $15 \mathrm{~mm} \mathrm{Hg}$ in 2 male participants, interestingly there were 4 male participants whose blood pressure difference after exercise was $20 \mathrm{~mm} \mathrm{Hg}$ furthermore there were 5 participants whose blood pressure difference after exercise were $30 \mathrm{~mm} \mathrm{Hg}$, while there were only 2 male participants whose blood pressure difference was $40 \mathrm{~mm}$ Hg similarly there were only 1 participant whose blood pressure difference after exercise was $50 \mathrm{~mm}$ Hg. It was seen that almost $60 \%$ male participants have $20-30 \mathrm{~mm} \mathrm{Hg}$ of blood pressure difference before and after exercise. From the total 15 female participants, there were 3 participants whose blood pressure difference were almost 10 $\mathrm{mm} \mathrm{Hg}$ after exercise as compared to before exercise, likewise there were 2 participants whose blood pressure difference was $30 \mathrm{~mm}$ Hg. Similarly 2 more female participants have their blood pressure raised up to $40 \mathrm{~mm} \mathrm{Hg}$ after exercise, interestingly there were 6 female participants whose blood pressure difference was $20 \mathrm{~mm} \mathrm{Hg}$, it was seen that $40 \%$ female participants have $20 \mathrm{~mm} \mathrm{Hg}$ difference in their blood pressure after exercise as compared to their blood pressure at rest.

From the graph it was clearly found that there was no significant difference in blood pressure after and before exercise among male and female participants, it showed there is similar response by the body of both male and female during exercise, similarly after statistical analysis it was found that there was no significant difference in blood pressure after exercise among ectomorph males and females.

According to the graph 1 there were 15 male participants, from which 1 has a difference of 5 BPM in HR after exercise, similarly there were only 1 participant whose HR was raised up to 13 BPM, likewise there was 1 participant whose HR was raised up to 22 BPM, 1 has raised up to 28 BPM, 1 has raised Up to 36 BPM, 1 has 37 BPM raised in HR after exercise as compare to resting $H R$, furthermore 1 has raised up to 41 BPM, 1 has raised up to 44 BPM, 1 has raised up to 45 BPM while 1 has raised up to 52 BPM, moreover 1 have 55 BPM increased in HR after exercise furthermore 2 participants have their HR raised up to 19 BPM after exercise similarly 2 participants have 56 BPM increased in HR after exercise.

There were 15 female participants, 1 has 4 BPM raised in HR after exercise, 1 has 10 BPM raised in HR likewise 1 has 11 BPM raised in HR similarly only 1 has
12 BPM raised in HR after exercise as compare to resting HR, there were 2 participants whose HR were raised up to 19 BPM likewise 2 more participants whose HR were raised up to 25 BPM, furthermore 1 participants has their HR raised up to 20 BPM likewise 1 participant HR was raised up to 26 BPM, there were 2 participants whose HR were raised up to 35 BPM, additionally there were only 1 participant whose HR was raised up to 29 BPM, 1 participant has 38 BPM difference in HR after exercise, similarly, one more participant has 55 BPM raised in HR after exercise as compare to resting $\mathrm{HR}$.

It was clearly seen that there was no significant difference between male and female heart rate after exercise as compare to resting heart rate, likely the statistical analysis also shows that there is no significant difference in exaggerated responses after exercise between male and female.

Because of small number of sample size this result could not be generalized on a large population, therefore similar studies need to be conducted on larger population.

Previously there were no studies done on exactly similar topic, precisely this new topic was choosen to find out the blood pressure response to exercise in both genders.

\section{CONCLUSION}

Blood pressure and heart rate are the two very important indicators in human body that give signal about many heart diseases which may or may not silently exist in one's body, but from this study we concluded that the body responses to exercise are similar in both male and female respectively, therefore both male and female have equal risk factors for heart diseases.

\section{REFERENCES}

[1] Hayward L. What is your body type: endomorph, mesomorph or ectomorph? [internet]. [cited 2015]. Available from: http://www.leehayward.com/body_types.htm

[2] Singh JP, Larson MG, Manolio TA, O'Donell CJ, Laver M, Evans JC, Levy D. Blood pressure response during treadmill testing as a risk factor for new-onset hypertension. Circulation. 1999:99:1831-1836

[3] O'Donnell CJ, Ridker PM, Glynn RJ, Berger K, Ajani U, Manson JE, Hennekens $\mathrm{CH}$. Hypertension and borderline isolated systolic hypertension increase risks of cardiovascular disease and mortality in male physicians. Circulation. 1997:95:1132-1137

[4] Garrison RJ, Kannel WB, Stokes J, Castelli WP. Incidence and precursors of hypertension in young adults: the framingham offspring study. Prev Med. 1987; 16:235-251 
[5] The sixth report of the joint national committee on prevention, detection, evaluation and treatment of high blood pressure. Arch Intern Med. 1997; 157:2413-2446

[6] Manolio TA, Burke GL, Savage PJ, Sidney S, Gardin JM, Oberman A. Exercise blood pressure response and 5-year risk of elevated blood pressure in a cohort of young adults: the cardia study. Am J Hypertens. 1994;7:234-241

[7] Tanji JL, Champlin JJ, Wong GY, Lew EY, Brown TC, Amsterdam EA. Blood pressure recovery curves after submaximal exercise: a predictor of hypertension at ten-year follow-up. Am J Hypertens. 1989;2:135-138

[8] Dlin RA, Hanne N, Silverberg DS, Bar-Or O. Follow-up of normotensive men with exaggerated blood pressure response to exercise. Am Heart J. 1983;106:316-320

[9] Kim YJ, Chun H, Kim CH. Exaggerated Response of Systolic Blood Pressure to Cycle Ergometer. Ann Rehabil Med. 2013;37(3):364-372

[10] American College of Sports Medicine. ACSM's guidelines for exercise testing and prescription. 8th ed. Philadelphia: Lippincott Williams \& Wilkins; 2010

[11] Ellestad MH. Stress testing: principles and practice. 5th ed. New York: Oxford University Press; 2003

[12] Garber CE, Blissmer B, Deschenes MR, Franklin $\mathrm{BA}$, Lamonte $\mathrm{MJ}$, Lee $\mathrm{IM}$, et al. American College of Sports Medicine position stand: quantity and quality of exercise for developing and maintaining cardiorespiratory, musculoskeletal, and neuromotor fitness in apparently healthy adults: guidance for prescribing exercise. Med Sci Sports Exerc. 201 1;43(7):1334-1359

[13] Fletcher GF, Balady GJ, Amsterdam EA, Chaitman B, Eckel R, Fleg J, et al. Exercise standards for testing and training: a statement for healthcare professionals from the American Heart Association. Circulation. 2001;104:1694-1740

[14] Kim C, Kim CH, Kim YJ. Effects of exercise type on hemodynamic responses and cardiac events in ACS patients. J Phys Ther Sci. 2014;4(4):609-614

[15] Balogun MO, Sulyman BO, Akinwusi PO. A comparison of the cardiovascular responses to treadmill and bicycle ergometer exercise in healthy male Nigerians. Afr J Med Med Sci. 1997;26:27-30

[16] Foster C, Gaeckle T, Braastad R, et al. First-pass radionuclide angiography during bicycle and treadmill exercise. J Nucl Cardiol.
1995;2:485-490

[17] Glassford RG, Baycroft GH, Sedgwick AW, et al. Comparison of maximal oxygen uptake values determined by predicted and actual methods. J Appl Physiol. 1965;20:509-513

[18] Maeder M, Wolber T, Atefy R, et al. Impact of the exercise mode on exercise capacity: bicycle testing revisited. Chest. 2005; 128:2804-2811

[19] McArdle WD, Katch FI, Pechar GS. Comparison of continuous and discontinuous treadmill and bicycle tests for max Vo2. Med Sci Sports. 1973;5:156-160

[20] Myers J, Buchanan N, Walsh D, et al. Comparison of the ramp versus standard exercise protocols. J Am Coll Cardiol. 1991;17:1334-1342

[21] Kurl SA, Laukkanen JA, Rauramaa R, Lakka TA, Sivenius J, Salonen JT. Systolic blood pressure response to exercise stress test and risk of stroke.2001;32(9):2036-2041

[22] Mundal R, Kjeldsen SE, Sandvik L, Erikssen G, Thaulow E, Erikssen J. Exercise blood pressure predicts mortality from myocardial infarction. Hypertension. 1996;27(1):324-329

[23] Mundal R, Kjedsen SE, Sandvik L, Eriksen G, Thaulow E, Erikssen J. Exercise blood pressure predicts cardiovascular mortality in middle-aged men. Hypertension. 1994;24:56-62

[24] Nobuyuki M, Arita M, Miyashita K, Morioka I, Shiraishi T, Nisho I. Blood pressure response to heart rate during exercise test and risk of future hypertension. Hypertension. 2002;39(3):761-766

[25] KuoTBJ, Lin T, Yang CCH, Li C, Chen C, Chou P American Journal of Physiology - Heart and Circulatory Physiology Published 1 December $1999 ; 277(6): 2233-2239$

[26] Smith U. Abdominal Obesity. J Clin Invest. 1983;72(3):1150-1162

[27] Kettles M, Cole CL, Wright BS. Women's health and fitness guide. USA: Human Kinetics; 2006

[28] Glendale Fire Department Health Centre. Bruce treadmill test protocol [internet]. [cited 2014]. Available from: https://www.glendaleaz.com/HealthCenter/documents/Bruce_treadmill_test_protocol.pdf

[29] Powers SK. Exercise physiology: theory and application to fitness and performance. 8th ed. USA: McGraw-Hill; 2012

[30] Fletcher GF, Ades PA, Kligfeild P, Arena R, Balady GJ, Bhittner VA, et al. Exercise standards for testing and training a statement for healthcare professionals from the American Heart Association. Circulation. 2013;128(8):873-934. 